\title{
A Comprehensive Understanding of Airflow in Non-Air-conditioned Bus Coaching System
}

\author{
Niranjana S J, Shivalingapa S Kubsad, Ravichandran G, Santhosh N
}

\begin{abstract}
Bus is a Major mode of transport in India and the passenger safety is significant during the travel. This Comprehensive comprehension on the literatures available discusses various parameters used to improve the Vehicle Design, Safety, Fuel Efficiency and decrease in drag of the vehicle. The outcomes obtained from CFD investigation is tabulated, and the exploratory outcomes obtained from aerodynamic tests are contrasted and numerical examination and the outcomes are additionally incorporated. The impact of temperature and the wind stream is likewise considered in this investigation. Various kinds of ventilations given in the transport vehicles are recorded, and the outcomes acquired from the various configurations in the structure is considered for opening and closing of Windows (Combination of windows). The cooling air inside the transport straightforwardly relies upon the outside climate condition. By overhauling the current vehicle transport model, the eco-friendliness will be improved and the drag power will be diminished.
\end{abstract}

Keywords: Drag force, CFD Analysis, Wind Tunnel Test, Vehicle Design, Fuel Efficiency.

\section{INTRODUCTION}

In this paper, from the inferences of available literature on wind tunnel examination, and Computational techniques, a better design optimization for bus is considered for analysis of the framework of the vehicle, since the bus mode of transport is a significant method of transport in India by an average citizen. The wind effect and cooling impact can be shutting that will put an indispensable job for the uniform wind stream [1], and inclusion of rooftop [2] in an appropriate position [4] that will eventually improve the drag characteristics, utilization of air screened entryways will improve the ventilation inside a transport [7] and furthermore giving HVAC conduits will upgrade the cooling impact [8]. The table of review of the journal papers shows that comfort of traveler will improve by considering the accompanying parameters. It's smarter to turn on the AC 15 minutes before travel begins [15].

Revised Manuscript Received on February 05, 2020.

* Correspondence Author

Niranjana S J, Assistant Professor, Department of Mechanical and Automobile Engineering at CHRIST (Deemed to be University), Bengaluru, Karnataka, India.

Dr. Shivalingappa S Kubsad, Professor and Head, Department, and $R \& D$ Head in various engineering colleges in Karnataka, India.

Ravichandran G, Assistant Professor, Department of Mechanical and Automobile Engineering at CHRIST (Deemed to be University), Bengaluru, Karnataka, India.

Dr. Santhosh N, Assistant Professor, department of Mechanical and Automobile Engineering, School of Engineering and Technology, CHRIST (Deemed to be University) Bengaluru, Karnataka, India.

(c) The Authors. Published by Blue Eyes Intelligence Engineering and Sciences Publication (BEIESP). This is an open access article under the CC BY-NC-ND license (http://creativecommons.org/licenses/by-nc-nd/4.0/) improved by the Combination of windows opening and

Research by S R Kale reveals that Air is entering from uncommon window and it is moving towards the driver with air speed of one tenth of vehicle speed and exit from the front window [3]. Drag power can be diminished by overhauling the vehicle design, especially in the frontal portion of the vehicle [6] [9] [10] [12] [13] [14].

J. Petzall et al in their paper have investigated different body shapes to improve the directional stability; cross breeze impact was a major issue in Sweden, part of accidents happened due to this phenomena, they carried out research on probe distinctive body shapes out of which they proposed that perfect state of the body incorporates adjusted front face, adjusted top sides and sharp back corners [5].

Borse S.H et al [20], in their paper worked on the effect of wind stream inside the vehicle utilizing suspension framework for compacted air to go about as an option for Air molding, In the vehicle design, aerodynamics will deal with drag forces, henceforth, it is necessary to diminish the drag force on vehicle utilizing cylinder and chamber course of action to control the vehicular movement.

Ravi Kumar et al [21], have researched on the scroll blower to enhance the drag force utilizations of cooling frameworks, in his research work, the current cylinder blower is supplanted with vitality proficient parchment blower; by utilizing this framework model, the weight on vehicle is decreased by $200 \mathrm{~N}$, power utilization is decreased upto 0.4 $\mathrm{kW}$, bringing about the eco-friendliness of the vehicle and improving the mileage by $0.5 \mathrm{kmpl}$. And furthermore the design helps in decrease of $\mathrm{CO} 2$ discharge. The yearly saving in the money on fuel cost of Rs. 6060 approx. is achieved for a mileage of 2500 kilometres.

Md Shahid Imam et al [22], have concluded that the pressure proportion diminishes with the expansion of refrigerant charge and evaporator air-side temperature increments with the expansion of condenser water temperature. The difference in blower Volumetric effective is inverse to that of pressure proportion.

Terry J. Hendricks et al [23], exhibited ability to foresee transient framework weights and Temperatures, mass stream rates, stream quality and stream system conditions, transient blower power, transient evaporator and condenser heat dissipation, and transient thermal conditions during the normal vehicle drive cycle conditions.

R. Farrington et al [30] have concluded that the cooling framework is the single biggest load on a vehicle that enhances the performance of the vehicle. Current cooling frameworks decrease the mileage of customary vehicles, in this manner steady enhancements can have a huge close term advantage as a result of the huge number of new automobiles sold every year. 
For high efficiency vehicles, current cooling frameworks have a totally inadmissible effect on mileage necessitating the need for development of new systems.

Thus, new researches are directed on an air stream test for the scaled brought down transport model, finding the speed appropriation and weight around the transport model. Utilizing that information, it is easy to determine the drag power and drag coefficient [18], the outcomes are approved by numerical connection. The exploratory outcome shows that weight achieves a most extreme incentive in the stagnation point over the middle area plane in its parallel planes; the weight drops pointedly at the front edge of the upper surface and further, it is somewhat expanded the downstream way [26]. The CFD and test results are thought about for the approval [29]. Eco-friendliness and mileage of the vehicle will improve by diminishing the drag.

\section{METHODOLOGY}

The practice for designing of passenger bus is very important to achieve safety and comfort of the passenger, the vehicle is subjected to various kind of loading condition such as stress, vibration and noise in different components. Author designed a Bus body with aluminium material, conducted FEA to find out the frequency, and they designed new structures with the aluminium material, frequency analysis is carried out on the model. They observed that $43.5 \%$ overall stress can be reduced with the altered one [12].

Prithiv Johan et al [1] have considered Non Air conditioned bus with 12 windows, they conducted experiential investigation, by opening all windows and found that the drag forces are greater, however by closing two windows the results are found to be optimized.

Further, they conducted CFD analysis with different combination of windows open, to achieve the optimum air flow, and concluded that six windows can be eliminated with $3 \%$ reduction in air velocity. With this windows area can be eliminated.

Roberto de Lieto Vollaro [7] have carried out investigations on climate conditions inside a city bus, conducted both numerical method and experimental investigation inside a bus at two different heights, one is at the siting position and another one is at standing position, temperature and air speed at two different location are closely matching. Author suggested to use air screened doors and windows for the better ventilation inside a bus, particularly in the traffic signals, bus stops etc.

Swapnil Khatavkar [11] have designed a bus body with aluminium material, conducted FEA to find out the frequency, and they designed new structures with the aluminium material, frequency analysis is carried out the model. They observed that $43.5 \%$ overall Stress can be reduced with the altered one.

Ramesh Kumar. A et al [28] have worked on the numerical study of the temperature field and air flow inside a passenger's cabin with different parameters using computational fluid dynamics (CFD) method. The main goal is to investigate the distribution of temperature and air flow with various parameters inside the passenger compartment in the steady-state conditions.

Kai Shen et al [24] have accomplished the task of analysis of flow field and have concluded that the rear engine cabin of the passenger car is much more complicated than the frontal cabin, the error is very lager if a typical $1 \mathrm{D}$ model is used in front engine cabin to simulate the cooling system. The Studies show that only the one-dimensional and three-dimensional coupling calculation method could make the results of the calculation of rear engine bus cooling system more accurate and it is much more suitable for engineering development and application.

Table 1. Methodologies to improve the comfort zone

\begin{tabular}{|c|c|c|}
\hline Researcher & $\begin{array}{l}\text { Different Parameters used to } \\
\text { improve the } \\
\text { comfort zone in a bus }\end{array}$ & $\begin{array}{c}\text { Reference } \\
\text { Number }\end{array}$ \\
\hline $\begin{array}{l}\text { Prithiv John et } \\
\text { al }\end{array}$ & $\begin{array}{l}\text { Combination of windows opening } \\
\text { and closing will improve the comfort } \\
\text { of passenger }\end{array}$ & 1 \\
\hline Vignesh S et al & $\begin{array}{l}\text { Providing roof vent comfort is } \\
\text { improved by } 131 \% .\end{array}$ & 2 \\
\hline $\begin{array}{l}\text { Roberto de } \\
\text { Lieto Vollaro }\end{array}$ & $\begin{array}{l}\text { Use of Air screened doors at different } \\
\text { location }\end{array}$ & 7 \\
\hline Wei Yang et al & Providing proper duct inside the bus & 8 \\
\hline Saban Unal & $\begin{array}{l}\text { In summer condition, AC (Air } \\
\text { Conditioner) needs to start at least } 15 \\
\text { minutes before traveling time. }\end{array}$ & 15 \\
\hline $\begin{array}{l}\text { Ali. Aliahmadi } \\
\text { et al }\end{array}$ & $\begin{array}{l}\text { Use of Heated Manikins in the coach } \\
\text { will improve the comfort. }\end{array}$ & 19 \\
\hline Borse S.H et al & $\begin{array}{l}\text { Use of compressed air from } \\
\text { suspension to act as alternate for Air } \\
\text { Conditioner. }\end{array}$ & 20 \\
\hline $\begin{array}{l}\text { N. E. A. Shafie } \\
\text { et al }\end{array}$ & $\begin{array}{l}\text { Use of air supply diffusers and air } \\
\text { return grills at front side of bus to } \\
\text { reduce the contaminants inside the } \\
\text { bus. }\end{array}$ & 25 \\
\hline $\begin{array}{l}\text { K.C. Nikam et } \\
\text { al }\end{array}$ & $\begin{array}{l}\text { Suggested use of open windows } \\
\text { inside city for lower velocity will } \\
\text { improve the comfort. }\end{array}$ & 27 \\
\hline
\end{tabular}

\section{RESULTS AND DISCUSSIONS}

In a bus coach the comfort, drag force reduction and Fuel efficiency is improved by redesigning the existing bus model, Start the engine at least twenty minutes before starting the journey, so that air-circulation is uniform and comfort is improved, by reducing the drag force the fuel efficiency can improve drastically, the following diagram shows the drag reduction and fuel efficiency details based on literature summary.

From the figures 1 and 2, we conclude that fuel efficiency will improve from $4 \%$ to $23 \%$ depending upon the vehicle design and also by avoiding the cross wind effect. 


\section{Drag Reduction Chart}

Drag reduce by

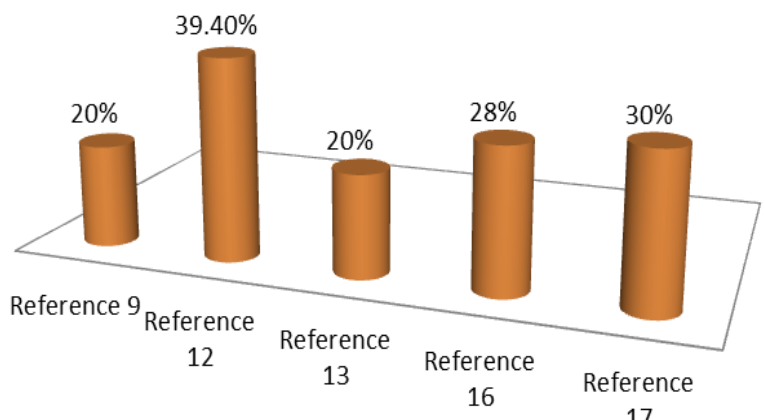

17

Figure 1. Drag Reduction chart

\section{Fuel Savings chart}

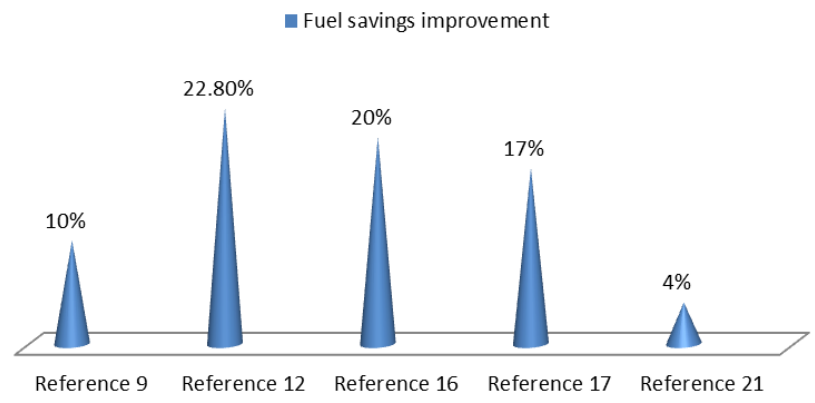

Figure 2. Fuel saving chart

\section{CONCLUSIONS}

After reviewing several research journals, the following points are concluded.

Drag force will reduce by redesigning on the vehicle body, and also by avoiding cross wind effect, fuel efficiency and comfort of a passenger will improve.

$>$ For better ventilation and comfort of passenger, switch on the AC before Ten Minutes from the Journey time.

$>$ Fuel efficiency of the vehicle will improve by reducing the drag force.

$>$ By adopting the different parameters mentioned in the introduction the ventilation inside the coach will improve and also passenger comfort will improve.

$>$ Numerical results and experimental results are almost close in some of the journal paper.

\section{REFERENCES}

1. Prithiv John, B Sriram, Senthil Kumar R, S Vinoth Kumar, and Prakash Ramasamy, (2013) "Ventilation Improvement in a Non-AC Bus", SAE International, 2013-01-2457.

2. Vignesh S, Vijay Ram C and Sachin P (2013), "Evaluation of Bus Ventilation Methods Using CFD”, SAE International, 2013-26-0043.

3. SR kale, SV veeravalli, HD punekar and MM yelmule, (2007) "Air flow through a non-airconditioned bus with open windows", $\mathrm{S}^{-}$adhan ${ }^{-}$a Vol. 32, Part 4, August 2007, pp. 347-363.

4. Marcus Thomas, Rajnish N Sharma, Michael Kilduff, (2006) "Aerodynamic Effects of Different Ventilation Methods on Buses", Forth International symposium on computatunal wind Engineering (CWE2006), Yokohama.

5. J. Petzall , P. Å. Torlund , T. Falkmer , P. Albertsson \& U. Bjornstig, (2008) "Aerodynamic design of high-sided coaches to reduce cross-wind sensitivity, based on wind tunnel tests", International Journal of Crashworthiness, Tylor and Francis, ISSN: 1358-8265 (Print) 1754-2111 (Online) Journal homepage: http://www.tandfonline.com/loi/tcrs20.

6. L.D.Jathar, K.C.Nikam, Dr. S. L. Borse, (2014) "Determination of Coefficient of Lift And Lift Force on Sedan Car Body by Changing Different Parameters Using Open Foam”, International Journal on Recent Technologies in Mechanical and Electrical Engineering (IJRMEE), ISSN: 2349-7947, Volume: 1 Issue: 5.

7. Roberto de Lieto Vollaro, (2013) "Indoor climate analysis for urban mobility buses: a CFD model for the evaluation of thermal comfort", International Journal of Environmental Protection and policy (1): 1-8, Published online May 2.

8. Wei Yang1, a, Wenku Shi1, b, Fuxiang Guo2, Weilong Yang2, (2012) "Flow Field Simulation and Performance Analysis of HVAC Defrosting Duct", 2nd International Conference on Electronic \& Mechanical Engineering and Information Technology (EMEIT-2012). Published by Atlantis Press, Paris, France.

9. Rodrigues, Antonio Flavio Aires, Gertz, Luiz Carlos, Cervieri, André, Telh, Marcus Aurelio, (2018) "Aerodynamic Analysis of a Vehicle Minibus", SAE International, 2014-36-0327.

10. J. Godwin John, A.Muthuvel, N. Prakash, (2014) "Numerical analysis for drag reduction in commercial buses", IOSR Journal of Mechanical and Civil Engineering (IOSR-JMCE) e- ISSN: 2278-1684, p-ISSN: 2320-334X, PP 01-05, www.iosrjournals.org.

11. Swapnil Khatavkar, Sanjay R. Kumbhar, Vaibhav V. Wakode, (2016) "Structural analysis of passenger bus body using FEA by changing joint structure for improving strength", International journal of current engineering and scientific research (ijcesr), ISSN (print): 2393-8374, (online): 2394-0697, volume-3, issue-6.

12. H. Yesfalgn Damissie, N. Ramesh Babu, (2017) "Aerodynamic Drag Reduction on Locally Built Bus Body using Computational Fluid Dynamics (CFD): A Case Study at Bishoftu Automotive Industry", International Journal of Engineering Research \& Technology (IJERT), ISSN: 2278-018, Vol. 6 Issue 11.

13. Devesh yadav,Sumit chauhan, Shashank karki, Satya ranjan nayak, Nitin kumar, S.Sudhakar babu, (2017) "CFD Analysis for Drag Force Reduction in Inter-City buses", International Research Journal of Engineering and Technology (IRJET), e-ISSN: 2395 -0056, Volume: 04 Issue: 05.

14. N. Govindha Rasu, A. M. Renil, S. J. Sachin, and J. kevin, (2016) "CFD analysis of commercial bus models for improvement of aerodynamic performance", Journal of Chemical and Pharmaceutical Sciences, ISSN 0974-2115, JCHPS Special Issue 3.

15. Şaban Unal, (2017) "An Experimental Study on a Bus Air Conditioner to Determine its Conformity to Design and Comfort Conditions", Journal of Thermal Engineering, Vol. 3, No. 1, pp. 1089-1101.

16. Siddhesh Kanekar, Prashant Thakre and E Rajkumar, (2017) "Aerodynamic study of state transport bus using computational fluid dynamics", IOP Conf. Series: Materials Science and Engineering 263 062052 doi:10.1088/1757-899X/263/6/062052.

17. Ashok Patidar, Umashanker Gupta, and Ankur Bansal, (2015) "Fuel Efficiency Improvement of Commercial Vehicle by Investigating Drag Resistance", SAE International, 2015-01-2893.

18. A F. Abdel Azim, El-Sayed and M M Nassief, (1996) "An Investigation into the Aerodynamics of the External Flow around a Bus (Daewoo Model)", SAE Techincal paper series, 962173.

19. Ali. Aliahmadi, Morteza Abdolzadeh, Khosro Lari, (2017) "Air Flow Simulation of HVAC System in Compartment of a Passenger Coach", Applied thermal doi.http;//dx.doi.org/10.1016//j.applthermaleng.2017.05.086.

20. Borse S.H, Satpute A.G, Mude J.M, Pokale R.S, Prof. Wabale A. D, Prof. Bhane A.B, (2015) "Air Conditioning system using vehicle suspension", International Journal of Recent Development in Engineering and Technology, Website: www.ijrdet.com ISSN 2347-6435(Online) Volume 4, Issue 4.

21. Ravi Kumar, Santosh G. Taji, GVS Sastry, (2014) "Deployment of Scroll Compressor in an Air Conditioning System of an SUV", International Journal of Engineering and Advanced Technology (IJEAT) ISSN: 2249 - 8958, Volume-3, Issue-3.

22. Md Shahid Imam, Dr.M.Shameer Basha, Dr.Md.Azizuddin, Dr. K.Vijaya Kumar Reddy, (2013) "Design of Air Conditioning System In Automobile", International Journal of Innovative Research in Science,Engineering and Technology, Vol. 2, Issue 12. 
23. Terry J. Hendricks, (2001) "Optimization of Vehicle Air Conditioning Systems Using Transient Air Conditioning Performance Analysis", Society of Automotive Engineers, Inc. 2001 -01-1734.

24. Kai Shen, Feihong Li, Jimin Ni, (2014) "1D/3D Coupling Calculation Analysis on Bus Cooling System", Energy and Power Engineering, 2014, 6, 550-556.

25. N. E. A. Shafie, H. M. Kamar and N. Kamsah, (2016) "Effects of air Supply Diffusers And Air Return Grilles Layout on Contaminants Concentration in Bus Passenger Compartment", International Journal of Automotive Technology, Vol. 17, No. 5, pp. 751-762, DOI 10.1007/s12239-016-0074-1.

26. McCallen R, Browand F, Ross J, (2002) "The aerodynamics of heavy vehicles: Trucks, buses and trains", (New York: Springer). Series: Lecture Notes in Applied and Computational Mechanics, Vol. 19.

27. K.C. Nikam and S.L. Borse, (2014) "Study of Air Flow through a Open Windows Bus Using OpenFOAM', International Journal of Fluids Engineering. ISSN 0974-3138 Volume 6, pp. 53-64.

28. Ramesh kumar.A, Jayabal.S and Thirumal.P, (2013) "CFD Analysis Of Air Flow And Temperature Distribution In An Air Conditioned Car", International Refereed Journal of Engineering and Science, Volume 2, Issue 4.

29. Zvar baskovic.U, Lorenz.M \& Butala.V, (2014) "Adiabatic flow simulation in an Air-conditioned vehicle passenger compartment", Series: Lecture Notes in Applied and Computational Mechanics, ISSN 1726-4529., Vol. 19.

30. Niranjana.S.J1, Smit Vishal Patel2, Ankur Kumar Dubey3, (2018) "Design and Analysis of Vertical Pressure Vessel using ASME Code and FEA Technique", IOP Conf. Series: Materials Science and Engineering 376, 012135 doi:10.1088/1757-899X/376/1/012135.

31. R. Farrington and J. Rugh, (200) "Impact of Vehicle Air-Conditioning on Fuel Economy, Tailpipe Emissions, and Electric Vehicle Range", Washington DC, NREL/CP-540-28960.G. O. Young, "Synthetic structure of industrial plastics (Book style with paper title and editor)," in Plastics, 2nd ed. vol. 3, J. Peters, Ed. New York: McGraw-Hill, 1964, pp. 15-64.

\section{AUTHORS PROFILE}

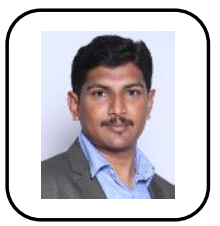

Niranjana $\mathbf{S} \mathbf{J}$, is pursuing his $\mathrm{PhD}$ at Atria Institute of Technology, Bengaluru, Karnataka, India which is affiliated to Visvesvaraya Technological University (VTU), Belagavi, Karnataka, India. He is presently working as an Assistant Professor, Department of Mechanical and Automobile Engineering at CHRIST (Deemed to be University), Bengaluru, Karnataka, India. His research area includes Design, Analysis of static and computational fluid dynamics. He has published two technical articles in international journals

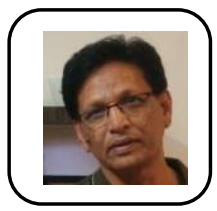

Dr. Shivalingappa S Kubsad, received his doctora degree in the year 2013 from Kuvempu University, Karnataka, India. He has worked as a Professor and Head of the Department, and R\&D Head in various engineering colleges in Karnataka, India. His research area includes Machine Design, Computational Fluid Dynamics. He has published nearly twelve research articles in peer reviewed Scopus indexed international journals.

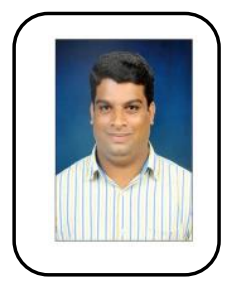

Ravichandran G, pursuing his $\mathrm{PhD}$ at ATME College of Engineering, Mysore, Karnataka, India which is affiliated to Visvesvaraya Technological University (VTU), Belagavi, Karnataka, India. He is presently working as an Assistant Professor, Department of Mechanical and Automobile Engineering at CHRIST (Deemed to be University), Bengaluru, Karnataka, India. His research area includes Polymer Matrix composites, Production and machine design. He has published eight technical articles in international journals and also published seven book chapters in international reference books.

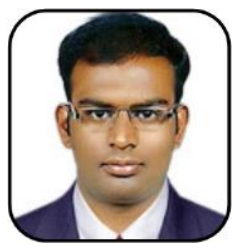

Dr. Santhosh N, currently working as an Assistant Professor in the department of Mechanical and Automobile Engineering, School of Engineering and Technology, CHRIST (Deemed to be University) has obtained his B.E., degree in Mechanical Engineering from Visvesvaraya Technological University, M.E., in Manufacturing Science and Engineering, and Ph.D., in Composite Materials from Bangalore University, He has to his credit more than 50 research articles published in
Scopus indexed journals of very high impact factor and most of them belonging to Elsevier and Springer Publications. He has authored several books and chapters and is a recipient of several awards and accolades for his outstanding work in the domain of materials research. He is also regarded as a good teacher and has developed teaching pedagogy and methodologies for content delivery in subjects of Materials Science, Machine Design, Kinematics of Machines and Dynamics. He is a member of several technical societies and is actively involved in disseminating scientific principles and knowledge. 